\title{
SHEAR CAPACITY OF RC BEAMS STRENGTHENED WITH EXTERNALLY BONDED FRP COMPOSITE SHEETS
}

The strengthening of concrete structures using fibre reinforced polymer (FRP) materials has become a growing area in the construction industry over the last few years. Valuable research work is going on all over the world.

This work is focused on theoretical, numerical and experimental analysis of the RC beam strengthened with a carbon fibre reinforced polymer (CFRP) sheet of the MBT-MBrace CF 640 type in a shear span of the RC beam.

The aim of this paper is to present a simple design approach of calculation of a CFRP sheet contribution to the shear capacity of the RC beams and to compare results with values obtained from numerical analysis based on the finite element method (FEM) with ATENA-2D program being employed and with experimental results.

The experiment confirms availability of CFRP sheets for shear strengthening of RC beams.

\section{Introduction}

Fibre-based composite materials (CM), often noted as fibre reinforced plastic (FRP), and their implementation in building industry are gaining on their popularity.

Low weight, flexibility, corrosion, magnetic and chemical resistance of the FRP materials are so much convincing that they are frequently used as an additional external reinforcement (e.g. lamella, sheet) or for strengthening of the RC beams, columns, slabs, walls, tunnels and soils, and in prestressed concrete. On the other hand, their cost is higher than the cost of common building materials.

Theoretical part is focused on mechanics of the uni-directional composite, on derivation of equations for further calculation of uni-directional composite properties in the fibre direction as well as in the transverse direction to fibres. The calculated values were used as material properties of CM to the numerical model. The ATENA-2D program based on FEM analyses, was used for numerical non-linear analysis.

Since the original work covers extended experiments, this paper presents only comparisons made on numerical and calculated values of the RC beams of one series. Additionally, a practical RC beam design approach with externally bonded carbon sheet will be introduced.

\section{Experimental program}

During experimental part, two different A and B series of three $\mathrm{RC}$ beams were prepared and tested (i.e., 3 beams of $\mathrm{A}$ series and 3 beams of B series) with $100 \times 300 \times 2700 \mathrm{~mm}$.
The A series has an internal shear reinforcement (stirrups). RC beams of the first A series were loaded to $70 \%$ of shear resistance of the RC beam. Then, the corrupted beams were repaired (closing shear cracks) and strengthened by added external shear reinforcement.

The B series (Fig. 1) had no internal shear reinforcement since the traditional shear reinforcement was replaced by external bonding of the MBT-MBrace CF 640 (old designation S\&P C Sheet 640) type. The main longitudinal reinforcement is of $2 \phi 16$ BST 500s. Four $700 \mathrm{~mm}$ carbon sheets of $150 \mathrm{~mm}$ width at the $250 \mathrm{~mm}$ axial distance were bonded in the shear area of the RC beams. The A4/B4 two-component epoxy resin was used for the bonding of carbon strips on concrete surface.

The epoxy resin has the following properties: compressive strength $f_{m, c}=85 \mathrm{MPa}$; tensile strength $f_{m, t}=35 \mathrm{MPa}$; modulus of elasticity $E_{m k}=9000 \mathrm{MPa}$; Poisson's ratio $\nu=0.37$; ultimate elongation $\epsilon_{m u}=0.0037$.

Properties of the MBT-MBrace CF 640 sheet are following: modulus of elasticity $E_{f, k}=640 \mathrm{GPa}$; Poisson's ratio $\nu=0.2$; tensile strength $f_{f y}=2650 \mathrm{MPa}$; ultimate elongation $\epsilon_{f u}=0.004$; theoretical thickness $t_{f}=0.190 \mathrm{~mm}$.

For design, the maximum strain of carbon fibers shall not exceed $0.2 \sim 0.3 \%$. Partial safety factor $\gamma_{s f}$ was considered $\gamma_{s f}=$ $=1.2$ for wet lay-up installation technique [1].

For concrete strength verification, 12 cubes with dimensions $150 \times 150 \times 150 \mathrm{~mm}$ were made. Compressive strength after 28 days was determined on 3 cubes. On 9 remaining cubes after following 213 days compression strength was determined.

\footnotetext{
* ${ }^{1}$ Patrik Kotula, ${ }^{2}$ Štefan Zemko

${ }^{1}$ Department of Building Constructions and Bridges, Faculty of Civil Engineering, University of Žilina, Komenského 52, 01026 Žilina, Slovakia. E-mail: kotula@fstav.utc.sk

${ }^{2}$ Osloboditelov 20, 01001 Žilina
} 


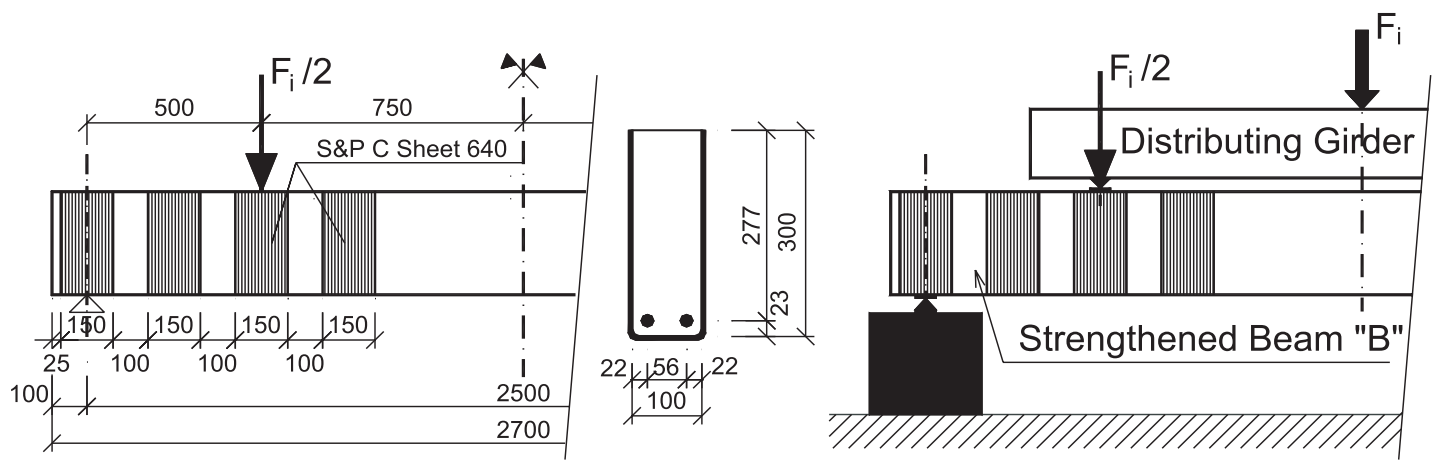

Fig. 1 RC beams - B Series

According to the compressive test, properties of the concrete are: $f_{c k}=46.652 \mathrm{MPa} ; f_{c d}=46.652 / 1.5=24.881 \mathrm{MPa} ; E_{c m}=$ $=33870.79 \mathrm{MPa} ; f_{c t k, 0.05}=2.345 \mathrm{MPa}$.

\section{Theoretical analysis}

Uni-directional composite laminate or sheet consists of two components: carbon fibres and epoxy resin create an anisotropic material with different stress-strain law in the fiber direction and in the transverse direction to fibers (Fig. 2).

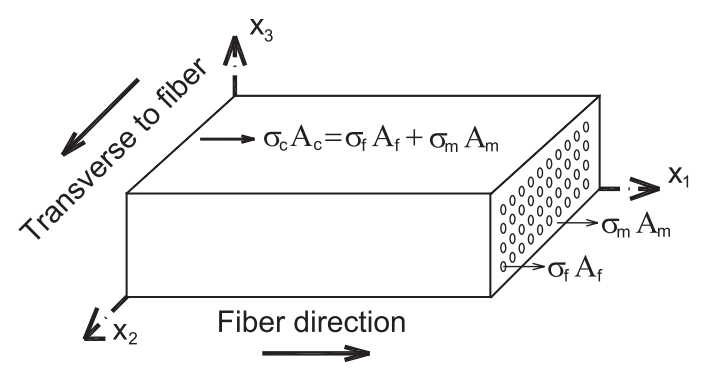

Fig. 2 Uni-directional composite laminate or sheet - stress in the fibre direction

Typical properties of the composite laminate or sheet:

- tensile strength in $x_{1}$,

- compressive strength in $x_{2}$,

- compressive strength in $x_{1}, \quad$ - shear strength in $x_{12}$.

- tensile strength in $x_{2}$,

Unitary volume of composite laminate or sheet $V_{c}$ is given by the sum of fibre volume $V_{f}$ and matrix volume $V_{m}$, Eq. (1):

$$
V_{c}=V_{f}+V_{m}=1
$$

Uni-direcftional composite laminate has two possible arrangements of fibers: square array of fibers or hexagonal array of fibers (Fig. 3).

The assumption that axial $x_{1}$ strain is the same for laminate, carbon fiber and matrix is used for determination of longitudinal
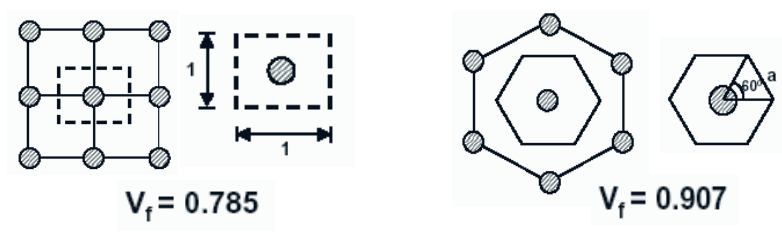

Fig. 3 Square and hexagonal array of fibres in a cross section of the composite laminate or sheet

modulus of elasticity $E_{1}$ of $\mathrm{CM}$ and Poisson's ratio $\nu_{12}$ and then the rule of mixtures:

$$
\begin{aligned}
& E_{1}=E_{c}=E_{f} V_{f}+E_{m}\left(1-V_{f}\right) \\
& \nu_{12}=\nu_{f} V_{f}+\nu_{m}\left(1-V_{f}\right)
\end{aligned}
$$

Providing that the transverse strain in laminate is the same as in matrix and fibres, so-called the rule of reciprocity can be used for determination of $E_{2}$ :

$$
\frac{1}{E_{2}}=\frac{V_{f}}{E_{f}}+\frac{\left(1-V_{f}\right)}{E_{m}}
$$

The assumption that shear stress is the same for laminate, carbon fiber and matrix is used for determination of $G_{12}$ :

$$
\frac{1}{G_{12}}=\frac{V_{f}}{G_{f}}+\frac{\left(1-V_{f}\right)}{G_{m}}
$$

Simple assumptions that arrangement of fibers in composite is ideal are is for derivation of formulas (4) and (5). Since the real composite laminate or sheet has not ideal arrangement of fibers, it is more appropriate to use a more precise one for determination of transverse properties of uni-directional CM according to [2]:

$$
\begin{aligned}
& E_{2}=E_{m} \frac{1+\xi_{1} \eta_{1} V_{f}}{1-\eta_{1} V_{f}} ; \eta_{1}=\frac{E_{f}-E_{m}}{E_{f}+\xi_{1} E_{m}} ; \\
& \xi_{1}=2 \text { - for fiber of circular section } \\
& G_{12}=\frac{G_{m} 1+\xi_{2} \eta_{2} V_{f}}{1-\eta_{2} V_{f}} ; \eta_{2}=\frac{G_{f}-G_{m}}{G_{f}+\xi_{2} G_{m}} ; \xi_{2}=2
\end{aligned}
$$

Ultimate tensile strength $F_{1, t}$ in the $x_{1}$ direction is determined from the ultimate elongations of fibers and used epoxy matrix, as shown in fig. 4. 

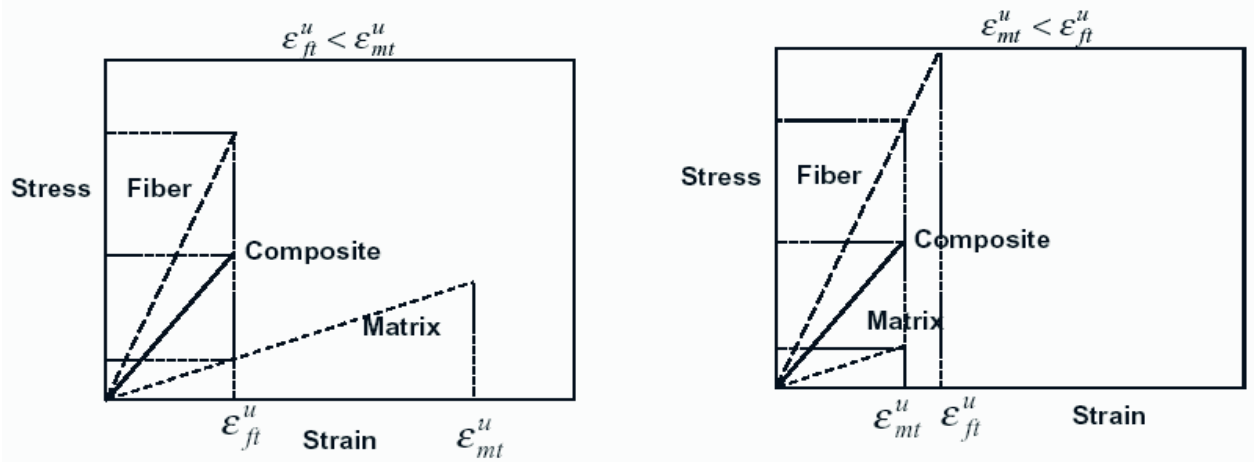

Fig. 4 Stress-strain diagram of CM for determining ultimate tensile strength $F_{l, t}$ depending on $\epsilon_{f t}^{u}$ and $\epsilon_{m t}^{u}$.

$$
\begin{aligned}
& F_{1, t}=E_{f} \epsilon_{f t}^{u} V_{f}+E_{m} \epsilon_{f t}^{u}\left(1-V_{f}\right) \text { if } \epsilon_{f t}^{u}<\epsilon_{m t}^{u} \\
& F_{1, t}=E_{f} \epsilon_{m t}^{u} V_{f}+E_{m} \epsilon_{m t}^{u}\left(1-V_{f}\right) \text { if } \epsilon_{f t}^{u}>\epsilon_{m t}^{u}
\end{aligned}
$$

Material properties of uni-directional composite sheets consisting of two components (MBT-MBrace CF 640 and epoxy resin A4/B4), obtained from Eq. (2), (3), (6)-(9) and (11), are presented in table 1 .

Properties of uni-directional composite sheets Table 1

\begin{tabular}{|l|c|c|c|c|}
\hline Fiber array in cross section & $\begin{array}{c}E_{1} \\
{[\mathrm{MPa}]}\end{array}$ & $\begin{array}{c}E_{2} \\
{[\mathrm{MPa}]}\end{array}$ & $\nu_{12}$ & $\begin{array}{c}F_{1, t} \\
{[\mathrm{MPa}]}\end{array}$ \\
\hline Square $\quad(V f=0.785)$ & 504335 & 91229.93 & 0.236 & 1916.473 \\
\hline Hexagonal $(V f=0.907)$ & 581317 & 189393.98 & 0.216 & 2029.005 \\
\hline
\end{tabular}

\section{Design shear equation}

The nominal shear strength $V_{R, R d}$ is expressed as the sum of three contributions given by the concrete $\left(V_{c, R d}\right)$, the shear steel reinforcement $\left(V_{s, R d}\right)$ and the FRP reinforcement $\left(V_{K M, R d}\right)$ :

$$
V_{R, R d}=V_{c, R d}+V_{s, R d}+V_{K M, R d}
$$

The first two terms of Eq. (12) according to Eurocode 2 [3] may be rewritten:

$$
\begin{aligned}
V_{c, R d} & =V_{R d 1}=\left[\beta \tau_{R d} k\left(1,2+40 \rho_{1}\right)-\right. \\
& \left.-0,15\left(N_{s d} / A_{C}\right)\right] b_{w} d \\
V_{s, R d} & =V_{w d}=\rho_{s w} f_{y w d} b_{w}(0,9 d)
\end{aligned}
$$

The design approach based on fracture of the FRP sheet is quite similar to the approach used to compute the contribution of steel shear reinforcement. Triantafillou [4] has presented an equation expressing FRP sheet contribution based on the stress concentrations in the sheet:

$$
V_{f}=\rho_{f} E_{f} \epsilon_{f e} b_{w} 0.9 d(1+\cot \beta) \sin \beta .
$$

In our case, Eq. (15) may be rewritten:

$$
V_{K M, R d}=\rho_{f} E_{1, e f} \epsilon_{K M, e f} b_{w} 0.9 d(1+\cot \beta) \sin \beta .
$$

where: $\rho_{f}=\left(2 t_{f} w_{f}\right) /\left(s_{f} b_{w}\right)$ - is FRP shear reinforcement ratio,

$\beta$ is the angle between the principal fiber orientation and longitudinal axis of the beam,

$t_{f}$ is the thickness of the FRP sheet on one side of the beam,

$w_{f}$ is width of the FRP strip,

$b_{w}$ is width of the beam cross section,

$s_{f}$ is spacing of the FRP strips,

$\epsilon_{K M, e f}$ is effective strain considered value 0.002 [1]

$\gamma_{s f}$ is partial safety factor considered $\gamma_{s f}=1.2$ of according to [1] for wet lay-up installation technique,

$E_{1, e f}$ je $E_{1} / 1.2=420279 \mathrm{MPa}$.

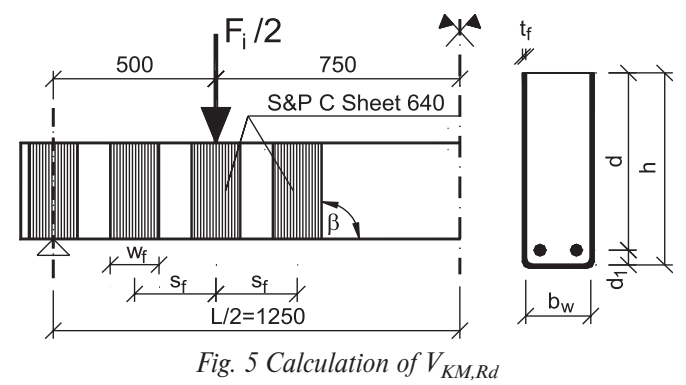

\section{Numerical analysis}

Numerical analysis for non-linear FEM calculations of the RC corrupted constructions has been solved by means of the program ATENA-2D. For this analysis, making a half beam model with a sustained symmetry is sufficient (Fig. 6).

A material model of concrete "Concrete-Sbeta Material" derived from CEB-FIP MC 90 and other sources [5] was assigned to the 2D macro-elements of thickness $0.1 \mathrm{~m}$. The main longitudinal reinforcement ( $2 \phi 16$ BST 500s) was modelled as uni-directional reinforcement element. 


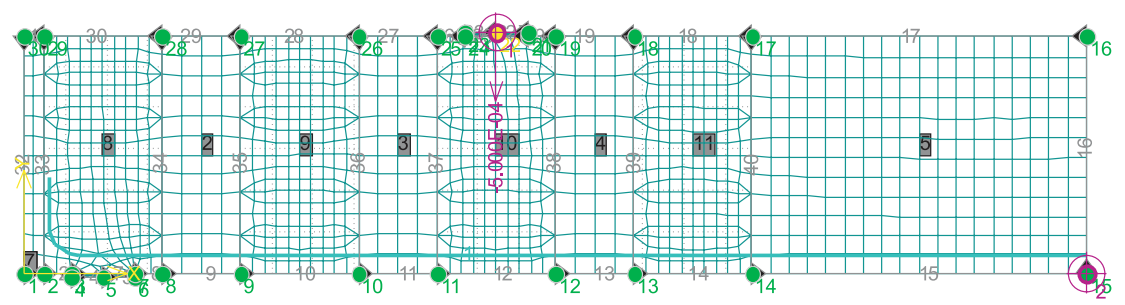

Fig. 6 Numerical model of the beam B series - ATENA-2D

In a good agreement with experiment, the model of composite sheet consists of two layers of smeared reinforcement in concrete arranged in defined strips (more densified net is depicted in Fig. 6). The first layer covers transverse properties of $\mathrm{CM}$ and the second layer the CM longitudinal properties of $\mathrm{CM}$.

The CM material constants are presented in table 1 . The volumes share of $V_{f}=0.785$ (square arrangement) was used in this case. Stress-strain diagrams of concrete and CM, used in numerical analysis are shown in Fig. 8.

Non-linear calculation was run until the $\mathrm{CM}$ fibre rupture, i.e. until reaching the $F / 2=64.25 \mathrm{kN}$ value (Fig. 9). The maximum shear crack on achievement of the fibre strain limit state was $w_{\max }=0.3198 \mathrm{~mm}$, which is higher than the limit crack width $\left(w_{\text {lim }}=0.3 \mathrm{~mm}\right)$ according to EC2.

\section{Result comparison}

From the non-linear FEM analysis it is clear that the most important for the ultimate shear capacity of the strengthened RC beam is the second ultimate state - the ultimate crack width. In table 2 there is a review of FEM calculated shear capacity values of strengthened and un-strengthened RC beams before achievement of the critical width of the shear crack $w_{\text {lim }}=0.3 \mathrm{~mm}$.

Contribution of the CM sheets from the equation (16) is higher when compared to the experiment. It follows that there is a strong need to correct the equation (16) in order to take into account the CM strain and the CM transverse load in a laminated part of the cross section. This will be a focus of further study.

Of course, there are more different ways of the CFRP sheet calculation based on mechanics of failure by the CM delamina- a)

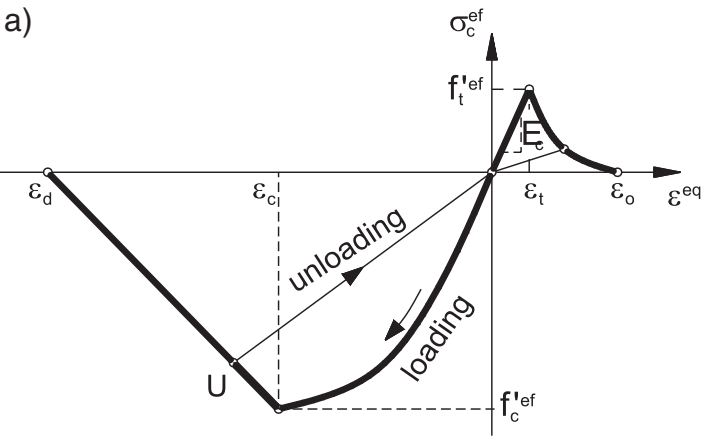

b)

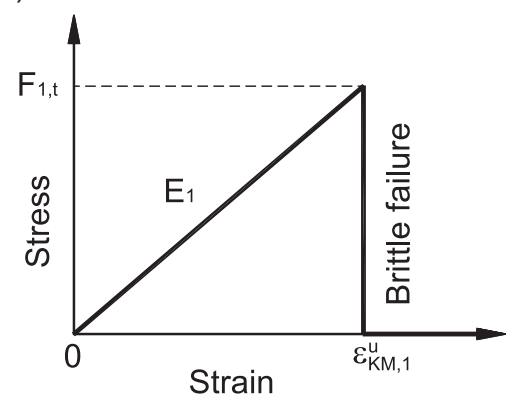

Fig. 8 Stress-strain diagrams used in ATENA-2D analysis: a) concrete, b) composite sheet in fibres direction

Krok 221, NosnikB CFRP

Skaláry: izoplochy, roz.výztu vrstva 2, v uzlech, Principal Engineering Strain S3, Max., <-6.720E-04:3.306E-03>[None]

Trhliny: v prvcích, otevení: $<-1.787 \mathrm{E}-063.918 \mathrm{E}-04>[\mathrm{m}]$, Sigma_N: $<-4.277 \mathrm{E}-01 ; 2.342 \mathrm{E}+00>[\mathrm{MPa}]$, Sigma_T: $<-2.345 \mathrm{E}+00 ; 2058 \mathrm{E}+00>[\mathrm{MPa}]$

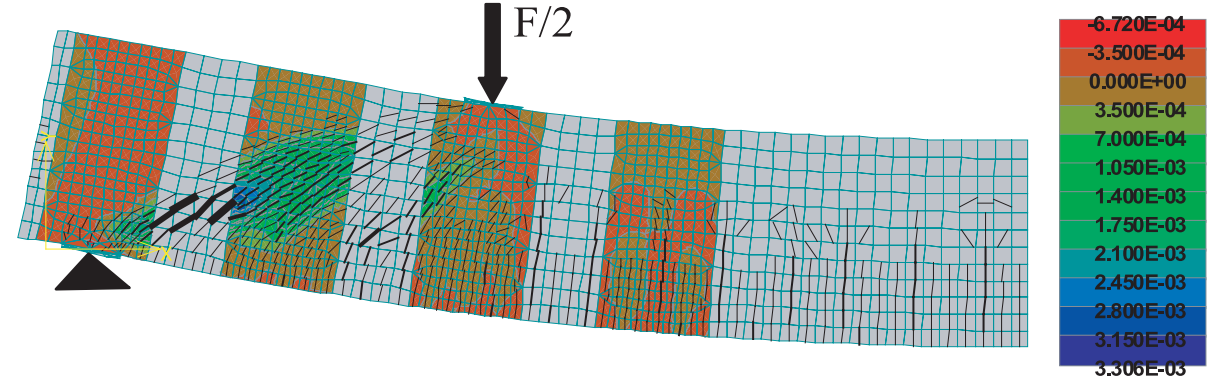

Fig. 9 Principal stress in composite sheets and development of shear and bending cracks obtained by the ATENA -2D 
The review of the results from the test and numerical calculation

Tab. 2

\begin{tabular}{|c|c|c|c|c|c|c|c|c|c|c|}
\hline & $\begin{array}{l}V_{R d 1} \\
(13) \\
{[\mathrm{kN}]}\end{array}$ & $\begin{array}{l}V_{w d} \\
(14) \\
{[\mathrm{kN}]}\end{array}$ & $\begin{array}{l}V_{K M, E d} \\
(16) \\
{[\mathrm{kN}]}\end{array}$ & $\begin{array}{l}V_{R, R d} \\
(12) \\
\\
{[\mathrm{kN}]}\end{array}$ & $\begin{array}{c}V_{A T, 1} \\
\text { no CFRP } \\
{[\mathrm{kN}]}\end{array}$ & $\begin{array}{c}\mathrm{V}_{\mathrm{AT}, 2} \\
\text { no CFRP } \\
w=0.184 \mathrm{~mm} \\
{[\mathrm{kN}]}\end{array}$ & $\begin{array}{c}V_{A T, 3} \\
\text { with CFRP } \\
\qquad[\mathrm{kN}]\end{array}$ & $\begin{array}{c}V_{A T, 4} \\
\text { with CFRP } \\
w=0.298 \mathrm{~mm} \\
{[\mathrm{kN}]}\end{array}$ & $\begin{array}{c}V_{A T, 5} \\
\text { with CFRP } \\
\epsilon=3.29 \cdot 10^{-3} \mathrm{~m} \\
{[\mathrm{kN}]}\end{array}$ & [kN] \\
\hline B1 & \multirow{3}{*}{38.614} & \multirow{3}{*}{ - } & \multirow{3}{*}{47.770} & \multirow{3}{*}{86.384} & \multirow{3}{*}{59.250} & \multirow{3}{*}{42.000} & \multirow{3}{*}{64.420} & \multirow{3}{*}{54.320} & \multirow{3}{*}{64.250} & 45.00 \\
\hline B2 & & & & & & & & & & 61.75 \\
\hline B3 & & & & & & & & & & 80.75 \\
\hline
\end{tabular}

Relationships between measured and calculated contributions of the used CFRP sheet

Tab. 3

\begin{tabular}{|c|c|c|c|c|c|c|}
\hline & $V_{\text {exp }} / V_{R, R d}$ & $V_{\text {exp }} / V_{A T, 1}$ & $V_{\text {exp }} / V_{A T, 2}$ & $V_{f, \text { exp }} / V_{A T, 3}$ & $V_{f \text { exp }} / V_{A T, 4}$ & $V_{f \text { exp }} / V_{A T, 5}$ \\
\hline B1 & 0.52 & 0.76 & 1.07 & 0.70 & 0.83 & 0.70 \\
\hline B2 & 0.71 & 1.04 & 1.47 & 0.96 & 1.14 & 0.96 \\
\hline B3 & 0.93 & 1.36 & 1.92 & 1.25 & 1.49 & 1.26 \\
\hline
\end{tabular}
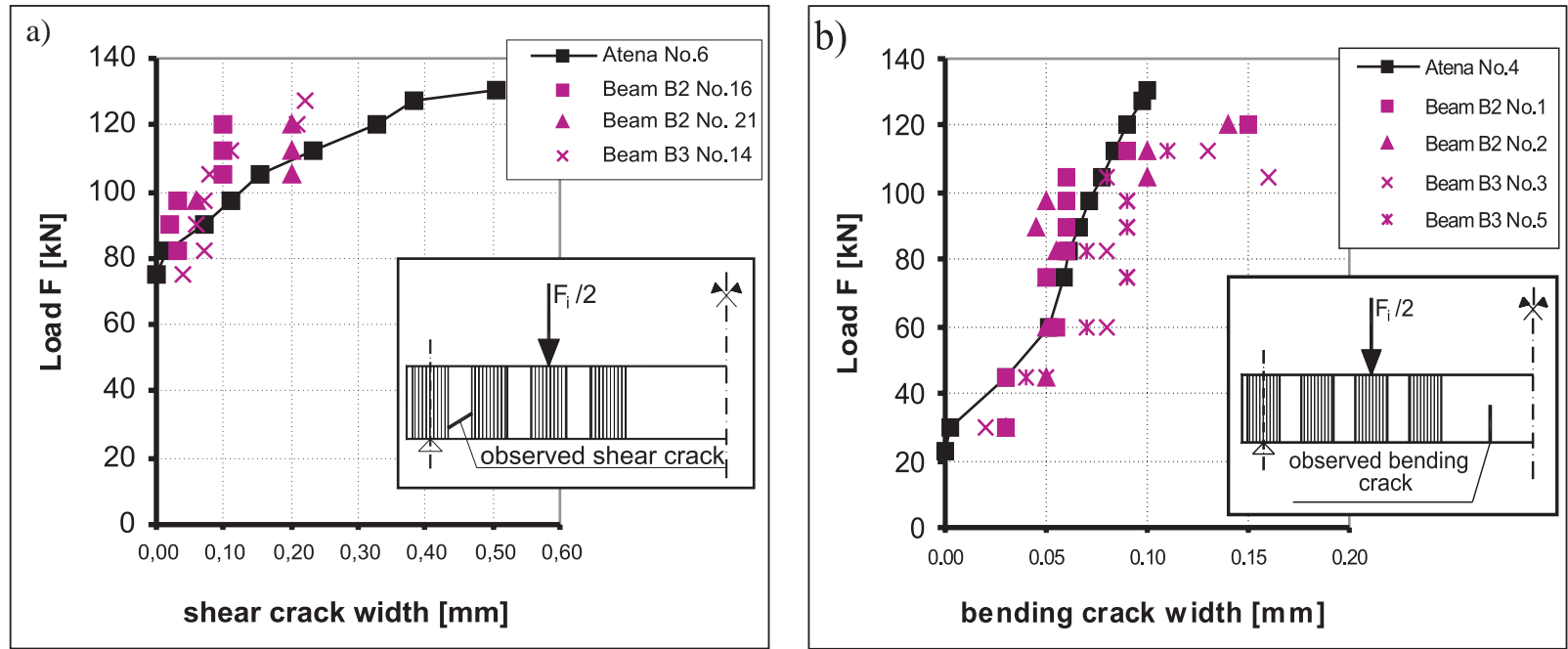

Fig. 10 Comparison of computed and measured widths of shear and bending cracks

tion from the concrete surface or by a combined effect of the $\mathrm{CM}$ delamination and rupture. These calculations give different $V_{K M, R d}$ values from the values presented in this paper. A detailed comparison is offered in [6].

Fig. 10a shows a development of shear crack width No. 6 obtained by the ATENA-2D program and measured values from the $\mathrm{B} 2$ and $\mathrm{B} 3$ beams. No similar crack occurred in the B1 beam. Fig. 10b shows development of the bending crack width No. 4 obtained by the ATENA-2D and measured values from the B2 and B 3 beams. Since the B1 beam was used only for testing purposes, its crack widths are not considered.

\section{Conclusions}

Conclusively, the externally bonded carbon sheet of the MBTMBrace CF 640 type is suitable as additional reinforcement for shear strengthening of RC beams.
The $\mathrm{RC}$ beams used in the experiment were damaged by shear, i.e. by delamination of $\mathrm{CM}$ sheet from the concrete surface and consequent development of a critical shear crack. Only in one case of the B3 beam damage of the carbon sheet was a result of rupture.

Differences in obtained ultimate shear loads of the beams of the same series were caused by the quality of sheet bonding.

The most important shear load criterion of the introduced 2D FEM model is excess of the limit width of the critical shear crack that appeared before the composite material rupture.

The experiments clearly show that adhesion between composite material and concrete surface has a significant effect on shear capacity of the strengthened RC beam.

In future we will focus on improvement of calculating the $\mathrm{CM}$ contribution to shear capacity of RC beams taking into account 
an effect of adhesion between composite material and concrete surface.

\section{Acknowledgements}

The research work presented in this paper has been supported by the Slovak Grant Agency, Grant VEGA SR No. 2/3035/23.

\section{References}

[1] Design guide FRP: Fiber reinforcement polymer for S\&P Products, June 2000, 70 p.

[2] HALPIN, J. C. - TSAI, S. W.: Effect of Environmental Factors on Composite Materials, AFML-TR, 1962

[3] STN P ENV 1992-1-1: Design of concrete structures, Part 1: General rules and rules for buildings, Bratislava, May 1999

[4] TRIANTAFILLOU, T. C.: Shear Strengthening of Concrete Members Using Composites, Non-Metallic (FRP) Reinforcement for Concrete Structures, Proceedings of the Third Symposium, Vol. 1, Japan, Oct 1997, p. 523-530.

[5] ATENA Program Documentation, PART 1, ATENA Theory Manual, CERVENKA CONSULTING, 2000

[6] KOTULA, P.: Shear Capacity of RC Beams strengthened with CFRP sheets (in Slovak), Proceedings of conference Staticko-konštrukčné a stavebno-fyzikálne problémy stavebných konštrukcií, Tatranská Lomnica, Vysoké Tatry, November 2003, p. 187-192, ISBN 80232-0221-9. 